\title{
Characterization of Fresh Cheese with Addition of Probiotics and Prebiotics
}

Natália Chinellato Azambuja ${ }^{1}$, Patrícia Blumer Zacarchenco ${ }^{1}$, Luciana Francisco Fleuri ${ }^{2}$, Juliana Cunha Andrade ${ }^{3}$, Izildinha Moreno $^{1}$, Ariene Gimenes Fernandes Van Dender ${ }^{1}$ and Darlila Aparecida Gallina ${ }^{1}$

1. Food Technology Institute-Dairy Technology Center (TECNOLAT-ITAL), Jardim Chapadão 13070-178, Campinas, São Paulo State, Brazil

2. Chemitry and Biochemistry Department, Institute of Biosciences, São Paulo State University “Júlio de Mesquita Filho” UNESP, Botucatu 18618-000, São Paulo State, Brazil

3. Food Technology Institute-Meat Technology Center (CTC-ITAL), Jardim Chapadão 13070-178, Campinas, São Paulo State, Brazil

Received: August 29, 2012 / Accepted: December 3, 2012 / Published: February 28, 2013.

\begin{abstract}
Sensorial and microbiological characteristics of a Brazilian fresh cheese samples with Bifidobacterium animalis subps. lactis as well as samples with this probiotic and polydextrose, a prebiotic ingredient, were evaluated. The addition of this microorganism was studied as: (1) lyophilized probiotic added to cheese curd and (2) by using milk previously fermented by this probiotic to produce the cheese. Cheese samples were microbiologically characterized after $0,7,14,21$ and 28 days of storage at a temperature of $4{ }^{\circ} \mathrm{C}$. The microbiological analyses conducted were quantification of total lactic acid bacteria, mesophilic microorganisms, Bif. animalis subps. lactis, coliforms at $30{ }^{\circ} \mathrm{C}$ and $45{ }^{\circ} \mathrm{C}$. Affective sensory test was conducted for two different cheese samples (with probiotic and with probiotic and prebiotic) as well as for control one week after manufacturing date. Cheese samples provided acceptable results for coliform counts at $30{ }^{\circ} \mathrm{C}$ and $45{ }^{\circ} \mathrm{C}$ in compliance with legislation. The cheese samples produced using milk fermented by probiotic showed counts of $10^{7}-10^{8} \mathrm{CFU} / \mathrm{g}$ after 28 days of storage, which assures functional property for this product to be claimed.
\end{abstract}

Key words: Probiotic, prebiotic, fresh cheese.

\section{Introduction}

The consumers' interest for food products with benefits for health has produced an increase in search of "functional" food, stimulating innovation and development of new products [1]. In Brazil, a large consumption of milk products is observed. Cheese production in our country was 801,440 tons in 2010 . Among fresh cheese types, $68 \%$ of production is represented by Minas-type fresh cheese [2]. Minas-type fresh cheese is one of the most important dairy products in Brazil, being considered as a truly national cheese. It

Corresponding author: Natália Chinellato Aambuja, research fields: dairy science and technology. E-mail: natalia.ferreira@fca.unicamp.br. is widely accepted in internal market and its simplified production technology makes this product very attractive for many industries [3].

Probiotic foods belong to functional food group. One of current definitions for probiotic is "live microbial food supplements which beneficially affects the host animal by improving its intestinal microbial balance" [4]. In order to obtain health benefits a daily dose of $10^{8}-10^{10}$ CFU of probiotic should be ingested, which represents consuming $100 \mathrm{~g}$ of food with at least $10^{6} \mathrm{CFU} / \mathrm{g}$ [5]. Most known bacteria with probiotic function in organism are those from Bifidobacterium and Lactobacillus genera [4]. There are technological advantages of using the probiotic 
species investigated in this paper such as good feasibility, compatibility with other lactic cultures, and tolerance to oxygen [6,7]. Haschke et al. [8] emphasized, among functional qualities of Bifidobacterium animalis subps. lactis (BB12), the excellent survival during intestinal transit as well as adhesion to enterocytes, which are essential conditions so a culture can be considered as probiotic.

Prebiotic is a term used to define food ingredients that are not hydrolysable or absorbed in the small intestine [8, 9] and which benefit the host by selectively stimulating bacterial growth and/or activity in the intestine favoring the growth of probiotics, mainly for lactobacilli and bifidobacteria. These substances are essentially composed by carbohydrate of different sizes from disaccharides and oligosaccharides to large polysaccharides.

Currently the prebiotics mostly used in studies and in commercial products are inulin, FOS (fructooligosaccharides) and polydextrose. Craig et al. [10] described polydextrose as an oligosaccharide formed by glucose polymers, defined as dietary fiber and belonging to the same class as inulin, both of low energy value.

According to Kolida, Gibson [11, 12], symbiotics are mixtures of probiotics and prebiotics, implying that the efficacy of each component will be

Milk heated in water bath in a vat previously sterilized at $35^{\circ} \mathrm{C}$

\begin{tabular}{|c|}
\hline$\Downarrow$ \\
\hline Cheese dough formation (Coagulation) \\
$\Downarrow$ \\
\hline Dough cutting with lyres \\
\hline$\Downarrow$ \\
\hline Serum removal/Clot separation \\
\hline Weighting \\
\hline$\Downarrow$ \\
\hline Shaping (Put clot into molds) \\
$\Downarrow$ \\
\hline Turning \\
\hline Package
\end{tabular}

established for a symbiotic formulation.

The purpose of this paper was evaluated two ways of incorporation of the probiotic BB12 to fresh cheese in order to improve industrial technology in cheese manufacture. By including the probiotic and, also, the prebiotic, the authors can offer to the consumers a fresh cheese containing health benefits instead of its intrinsic nutritional value. The centesimal composition, as well as physical, chemical and sensory properties was evaluated.

\section{Material and Methods}

\subsection{Materials}

Cheese elaboration: Milk used in process was low-fat, homogenized and pasteurized type milk. Two processing types were conducted, in which three cheese formulations were prepared with $3 \mathrm{~kg}$ per treatment. Steps for cheese obtainment are detailed below based on control cheese flowchart (Fig. 1), as per the technique recommended by Furtado and Lourenço-Neto [13].

In Q1 (probiotic cheese) treatment, lyophilized probiotic culture Bifidobacterium animalis subps. Lactis. (BB12 - Christian Hansen) was added into Minas-type fresh cheese curd. These cheese samples from Q1 treatment were obtained by the same method

Addition of: lactic acid $30 \mathrm{~mL}$, calcium chloride $6 \mathrm{~mL}$, and rennet $11 \mathrm{~mL}$ diluted in sterile water $200 \mathrm{~mL}$

Fig. 1 Flowchart of control cheese (with no addition of probiotic and prebiotic) 
as control cheese (Fig. 1). After curd weighting, lyophilized culture was added at a previously calculated concentration in order to obtained $10^{8} \mathrm{CFU} / \mathrm{g}$ in final product. This concentration was determined by quantification of the viable cells in the lyophilized culture: BB12 culture was previously dispersed in $0.01 \%$ peptonated water, then it was plated in MRS (Man Rogosa Sharp) agar modified as described by Antunes et al. [7] for probiotic count. In Q2 treatment, probiotic culture was inoculated in milk and incubated overnight at probiotic and prebiotic cheese $35-37{ }^{\circ} \mathrm{C}$ so milk fermentation could occur reaching $\mathrm{pH}$ of 5.7-5.8 before cheese samples were obtained by acid coagulation conducted in previous treatments, control and Q1. Also, in treatment Q2, polydextrose prebiotic (Danisco) was added at an amount of $60 \mathrm{~g}$ for $1.2 \mathrm{~kg}$ cheese dough. Then, prebiotic was diluted into 300 $\mathrm{mL}$ of cheese whey and added before final product salting. It was produced two batches of the three cheeses.

\subsection{Methods}

\subsubsection{Microbiological Analyses}

Microbiological analyses were conducted in duplicate according with the methodology described in Michael \& Frank [14] during 28 days of storage on the following time points: days $0,7,14,21$ and 28 . Analyses conducted were coliform count at $30{ }^{\circ} \mathrm{C}$ and $45{ }^{\circ} \mathrm{C}$ by the MPN (most probable number) method, total mesophilic microorganisms count in PCA (plate count agar) and lactic acid bacteria count in MRS agar. These analyses were performed in milk, raw material and control cheese. All three treatments, control cheese, Q1 and Q2, were prepared at the same time. Therefore samples for total count, coliform at $30{ }^{\circ} \mathrm{C}$ and $45^{\circ} \mathrm{C}$ and thermotolerant coliforms $\left(45^{\circ} \mathrm{C}\right)$ count and lactic acid bacteria count were obtained from control cheese.

\subsubsection{Quantification of BB12 in Cheese Samples}

According with modification made by Antunes et al. [7], the quantification of BB12 was conducted in Man
Rogosa Sharp Agar supplemented by 10\% HCL L-cysteine, 10\% lithium chloride, and aniline blue dye. Incubation was made under anaerobic conditions using one anaerobiosis jar with gas generator for anaerobiosis (Anaerogen, Oxoid/Interlab) for $72 \mathrm{~h}$ at a temperature of $45^{\circ} \mathrm{C} \pm 1{ }^{\circ} \mathrm{C}$.

\subsubsection{Sensory Analysis}

This analysis was conducted in accordance with legal proceedings on enrollment in Research Ethics Committee under protocol number 350/2011. Sensory evaluation of control, Q1 and Q2 cheese samples was performed after one week of manufacturing. Affective test was applied as described by Meilgaard et al. [15].

The test was conducted with 33 male and female panelists of 21 to 50 years old, not previously trained, with the purpose of evaluating the acceptance of products obtained on a hedonic scale (nine corresponding to "I liked very much" and one corresponding to "I disliked very much"). Each panelist was given two cubes $(2 \mathrm{~cm})$ of each Minas-type fresh cheese treatment (control, Minas-type cheese with addition of lyophilized probiotic Q1 and Minas-type cheese with addition of probiotic and prebiotic Q2) in a $50 \mathrm{~mL}$ disposable glass coded with a 3-digit number. Together with the samples, each panelist received a glass of water (200 $\mathrm{mL}$ ) at room temperature and one cracker type biscuit to be used between samples evaluations. Analyses have occurred in separate cabins illuminated by white light. The panelist was requested to evaluate each coded sample, comparing it with the others in order to indicate the degree of difference between the samples in the following attributes: overall, odor, texture, and taste. At the end of evaluation, the panelist was requested to organize the samples as the one he/she liked the least (1) liked (2) and liked the most (3) by rank test with the purpose of verifying if treatments were different between each other.

Results were evaluated by ANOVA (Analysis of Variance) and Tukey's test at a confidence level of 
95\% $(P \leq 0.05)$ to check if there is any difference between Minas-type fresh cheese treatments.

\subsubsection{Physical-Chemical Analysis}

After processing, control cheese, Q1 and Q2 were characterized for the following physical and chemical parameters: $\mathrm{pH}$ by a digital potentiometer B375 (Micronal), total dry matter by gravimetric methodology, ash content by drying in mufla oven at $550{ }^{\circ} \mathrm{C}$, titratable acidity in lactic acid, total nitrogen by Kjeldahl method; all analyses have followed the methodology described by physical-chemical analysis manual of Instituto Adolfo Lutz [16]. Nitrogen values were multiplied by 6.38 factor to obtain equivalent values for protein, carbohydrate and humidity by method of difference and sodium chloride determined by Volhard method as described by Pereira [17]. All physical-chemical analyses were conducted in triplicate.

\section{Results and Discussion}

\subsection{Microbiological Analysis}

Microbiological analyses conducted for low-fat, homogenized, and pasteurized type A milk used as raw material for cheese preparation allowed to verify their compliance to Brazilian legislation [17], with counts for total mesophilic microorganisms and acid lactic bacteria of $<10 \mathrm{CFU} / \mathrm{mL}$ and coliform at $30{ }^{\circ} \mathrm{C}$ and $45{ }^{\circ} \mathrm{C}$ of $<0.3 \mathrm{NMP} / \mathrm{mL}$. Table 1 shows values regarding microbiological analyses conducted to characterize cheese samples obtained after processing.

As per the results shown in Table 1, cheese samples had counts within minimum hygienic sanitary standards established in the Brazilian legislation [18]. These microbiological conditions were achieved due to characteristics of milk used, which are described above. Cheese samples were elaborated according with good manufacturing practices, with raw material playing an important role on cheese quality since it had a good hygienic sanitary quality.

Table 2 shows Bif. animalis subps. lactis. counts in Q1 and Q2 cheese samples during storage time.

Q1 and Q2 cheese samples with probiotic had counts around $10^{7}-10^{8} \mathrm{CFU} / \mathrm{g}$, except for one Q1 batch. These are encouraging results since, as mentioned by Antunes et al. [7], bifidobacteria are fastidious microorganisms with low survival under

Table 1 Microbiological characterization of control cheese elaborated in processing 1 and processing 2 (repetition) during storage period.

\begin{tabular}{|c|c|c|c|c|c|c|c|c|}
\hline \multirow{2}{*}{$\begin{array}{l}\text { Storage } \\
\text { Time }\end{array}$} & \multicolumn{2}{|c|}{$\begin{array}{c}\text { Total mesophilic microorganisms' } \\
\text { count }(\mathrm{CFU} / \mathrm{g})\end{array}$} & \multicolumn{2}{|c|}{$\begin{array}{c}\text { Acid lactic bacteria count } \\
(\mathrm{CFU} / \mathrm{g})\end{array}$} & \multicolumn{2}{|c|}{$\begin{array}{c}\text { Coliform count at } 30-35^{\circ} \mathrm{C} \\
(\mathrm{NMP} / \mathrm{g})\end{array}$} & \multicolumn{2}{|c|}{$\begin{array}{c}\text { Coliform count at } 45^{\circ} \mathrm{C} \\
(\mathrm{NMP} / \mathrm{g})\end{array}$} \\
\hline & Proc. 1 & Proc. 2 & Proc. 1 & Proc. 2 & Proc. 1 & Proc. 2 & Proc. 1 & Proc. 2 \\
\hline 0 & $8.10 \times 10^{2}$ & $1.09 \times 10^{3}$ & $<10$ & $<10$ & 43 & $<3.0$ & $<3.0$ & $<3.0$ \\
\hline 7 & $2.50 \times 10^{5}$ & $7.00 \times 10^{2}$ & $1.85 \times 10^{5}$ & $<10$ & 23 & 9.2 & $<3.0$ & $<3.0$ \\
\hline 14 & $1.06 \times 10^{6}$ & $1.10 \times 10^{3}$ & $2.22 \times 10^{5}$ & $<10$ & 23 & 43 & $<3.0$ & $<3.0$ \\
\hline 21 & $1.95 \times 10^{7}$ & $4.30 \times 10^{5}$ & $1.00 \times 10^{6}$ & $1.23 \times 10^{3}$ & $>1,100$ & 23 & $<3.0$ & $<3.0$ \\
\hline 28 & $4.50 \times 10^{9}$ & $7.00 \times 10^{6}$ & $2.27 \times 10^{7}$ & $3.30 \times 10^{4}$ & $>1,100$ & $>1,100$ & $<3.0$ & $<3.0$ \\
\hline
\end{tabular}

$\mathrm{CFU} / \mathrm{g}=$ Colony-Forming Unit per gram of cheese analyzed.

Table 2 BB12 probiotic culture count in MRS Agar modified in probiotic (Q1) and probiotic with prebiotic (Q2) cheese samples.

\begin{tabular}{|c|c|c|c|c|}
\hline \multirow{2}{*}{ Storage Time } & \multicolumn{2}{|c|}{ Probiotic cheese (Q1) (CFU/g) } & \multicolumn{2}{|c|}{ Probiotic and prebiotic cheese (Q2) (CFU/g) } \\
\hline & Proc. 1 & Proc. 2 & Proc. 1 & Proc. 2 \\
\hline 0 & $1.40 \times 10^{8}$ & $2.20 \times 10^{8}$ & $9.50 \times 10^{7}$ & $4.10 \times 10^{9}$ \\
\hline 7 & $1.95 \times 10^{7}$ & $3.00 \times 10^{8}$ & $9.50 \times 10^{6}$ & $9.20 \times 10^{8}$ \\
\hline 14 & $2.60 \times 10^{8}$ & $2.02 \times 10^{7}$ & $1.20 \times 10^{7}$ & $1.49 \times 10^{9}$ \\
\hline 21 & $6.50 \times 10^{8}$ & $6.40 \times 10^{6}$ & $6.30 \times 10^{7}$ & $1.18 \times 10^{9}$ \\
\hline 28 & $6.30 \times 10^{8}$ & $1.70 \times 10^{5}$ & $3.30 \times 10^{7}$ & $9.50 \times 10^{8}$ \\
\hline
\end{tabular}

$\mathrm{CFU} / \mathrm{g}=$ Colony-Forming Unit per gram of cheese analyzed. 
certain conditions, therefore BB12 culture was chosen for this research, since it is industrially used as probiotic in yogurts, fermented milk, cheese, beverages, sauce, diet supplements, infant formula and cereal for over 10 years. BB12 strain used in this study showed appropriate populations resisting to barriers such as oxygen during processing incorporation.

Minas-type fresh cheese samples of this study that had probiotic and prebiotic (Q2) showed count values around $10^{7}-10^{8} \mathrm{CFU} / \mathrm{g}$ after 28 days of storage at $4{ }^{\circ} \mathrm{C}$. Cheese samples with prebiotic and probiotic Q2 were obtained from milk fermented by BB12, which enables to reduce the lyophilized culture amount used by the industries. Investigations such as the one conducted by Buriti [20] evaluated the use of lyophilized probiotic added in symbiotic cream fresh cheese only.

Capela et al. [21] have verified that by adding $2 \%$ of fiber such as inulin, corn resistant starch and oligofructose, viability of Lactobacillus acidophilus, Lactobacillus casei, Bifidobacterium longum and Lactobacillus rhamnosus GG strains was increased in yogurt in comparison with control yogurt with no addition of fiber during 4 weeks of storage at $4{ }^{\circ} \mathrm{C}$. Buriti et al. [22] have studied probiotic fresh cream cheese samples added or not with prebiotic and have not found differences in probiotic survival during storage between cheese samples with and without prebiotic.

Considering the requirements of the Brazilian legislation for functional foods [22], cheese samples with probiotic have shown a potential to functional property to be claimed.

\subsection{Sensory Analysis}

Most panelists $(54.6 \%)$ who have evaluated the products were within age group of 21 to 30 years old. The frequency of consumption for this type of product may be considered as high: $63.3 \%$ consume it on a weekly and biweekly basis.

Table 3 shows results for sensory analysis, conducted on 7 days of storage for different treatments of Minas-type fresh cheese, as follows: (1) control, (2) Minas-type fresh cheese with addition of probiotic (Q1), and (3) Minas-type fresh cheese with addition of probiotic and prebiotic $(\mathrm{Q} 2)$.

By analyzing the results described in the table above, samples were not significantly different $(P>$ $0.05)$ in overall, odor and flavor attributes. These results allow to infer that the probiotic BB12 to the cheeses will not interfere in their acceptance by consumer in market.

On the other hand, as expected for cheese with addition of prebiotic (fiber) (Q2) the authors observed that panelists noticed cheese consistency was different in comparison with Q1 and control; however, even with this statistical difference such cheese had a higher score for texture attribute than other cheese samples.

When compared with studies performed by other researchers, sensory changes were irrelevant among different samples evaluated. In a study conducted by Buriti [20], the use of probiotic cultures has not caused sensory changes in fresh cream cheese samples

Table 3 Sensory evaluation results.

\begin{tabular}{llll}
\hline Attributes & \multicolumn{3}{c}{ Treatments } \\
\cline { 2 - 4 } & Control & Q1 & Q2 \\
\hline Overall & $5.67^{\mathrm{a}} \pm 2.16$ & $5.91^{\mathrm{a}} \pm 2.01$ & $6.48^{\mathrm{a}} \pm 2.00$ \\
Odor & $6.06^{\mathrm{a}} \pm 1.80$ & $6.36^{\mathrm{a}} \pm 1.67$ & $6.58^{\mathrm{a}} \pm 1.89$ \\
Texture & $5.03^{\mathrm{b}} \pm 2.38$ & $5.12^{\mathrm{b}} \pm 2.29$ & $6.64^{\mathrm{a}} \pm 1.80$ \\
Flavor & $5.64^{\mathrm{a}} \pm 1.88$ & $5.67^{\mathrm{a}} \pm 1.87$ & $5.70^{\mathrm{a}} \pm 2.39$ \\
\hline
\end{tabular}

Overwritten letters in the same line means there is no significant difference between samples evaluated $(\mathrm{p} \leq 0.05)$. Scale ranging from $9-$ I liked very much to $1-$ I disliked very much. 
Table 4 Physical-chemical characterization of control, probiotic (Q1) and probiotic added with prebiotic (Q2) after processing cheese samples

\begin{tabular}{lccc}
\hline \multirow{2}{*}{ Analyses } & \multicolumn{2}{c}{ Treatments } \\
\cline { 2 - 4 } & Control & Q1 & Q2 \\
\hline $\mathrm{pH}$ & 6.47 & 5.32 & 0.32 \\
Acidity & $0.103 \pm 0.000$ & $0.512 \pm 0.000$ & $0.102 \pm 0.000$ \\
Ashes (g/100g) & $3.856 \pm 0.029$ & $3.118 \pm 0.064$ & $3.636 \pm 0.076$ \\
Total protein (g/100g) & $26.726 \pm 0.849$ & $25.508 \pm 0.150$ & $26.430 \pm 0.493$ \\
Total dry stratum (g/100g) & $35.398 \pm 0.494$ & $35.807 \pm 0.733$ & $35.634 \pm 0.529$ \\
Salt (g/100g) & $1.288 \pm 0.014$ & $1.128 \pm 0.015$ & $1.153 \pm 0.045$ \\
Humidity (\%) & $64.602 \pm 0.494$ & $64.193 \pm 0.733$ & $64.367 \pm 0.529$ \\
\hline
\end{tabular}

after 7 days of storage at a temperature of $4{ }^{\circ} \mathrm{C}$. According with results obtained after performing the sensorial test, no significant difference $(P>0.05)$ was observed among samples evaluated in comparison with control sample. However, most panelists rated the samples evaluated with the attribute "I liked".

\subsection{Physical-Chemical Analysis}

Table 4 shows the results for physical-chemical characterization of cheese samples produced in this study.

Contents of humidity, ashes, total protein, dry matter, salt and $\mathrm{pH}$ for the three types of cheese produced in this study did not show any significant difference even with the variations among cheese samples (addition of probiotic in Q1 and addition of probiotic and prebiotic in Q2). In accordance with Brazilian Law [23], Minas-type fresh cheese is a product of very high humidity content and may show values above $55 \%$. Cheese samples produced in this study fall within this characteristic. By studying symbiotic cream cheese with the addition of probiotic and prebiotic at various amounts, Alves [25] observed that cheese formulations have not had significant differences for physical-chemical characteristics as fat, ashes, and protein, in comparison with control treatment.

\section{Conclusion}

The cheeses with prebiotic and probiotic Q2 were obtained from milk fermented by the probiotic BB12, which enables to reduce the lyophilized culture amount used by the industries. This finding was reinforced by the sensorial scores of the cheeses Q2 and Q1 (containing lyophilized probiotic) that were statistically equal. The probiotic used in this study was technologically appropriate for application in Minas-type fresh cheese, as it showed appropriate populations resisting to barriers such as oxygen during processing incorporation. The addition of probiotic culture and prebiotic studied will not interfere in the consumer acceptance of the cheese. Consequently, the authors have verified that this study was conducted as expected in order to offer to the market a value-added product with benefits for consumer health, since cheese is highly consumed in the country.

\section{Acknowledgments}

The authors' special thanks to ITAL (Instituto de Tecnologia de Alimentos), which has provided labs and pilot plants for conduction of this study and especially to the department TECNOLAT (Centro de Tecnologia de Laticínios) and CTC (Centro de Tecnologia de Carnes).

\section{References}

[1] C. Disney (Organizer), Brazilian Association of Cheese Industry (ABIQ), São Paulo, São Paulo State, Brazil, Jan. 20, 2011, Source: Nielsen, Desk Research-Ad Hoc. Research, Imports: CONIL/SINDLEITE/SECEX, 2010.

[2] J.D.G. Carvalho, Evaluation of the quality of minas frescal cheeses elaborated by technological processes differents and commercialized in Campinas-SP, Master Thesis [Online], Faculty of Food Engineering, State University of Campinas, São Paulo State, Brazil, 2003, http://www.bibliotecadigital.unicamp.br/document/?code 
$=$ vtls000293690 (acessed Sept. 20, 2011).

[3] T. Mattila-Sandholm, P. Myllärinen, R. Crittenden, G. Mogensen, R. Fondén, M. Saarela, Technological challenges for future probiotic foods, International Dairy Journal 12 (2002) 173-182.

[4] M.T.B. Pacheco, V.C. Sgarbieri, Fiber and Gastrointestinal Diseases, in: F.M. Lajolo et al., Dietary Fiber at Iberoamerica, Technology and health: production, characterization, phisiologycal effect and food application, Varela, São Paulo, 2001, pp. 385-397.

[5] G. Reid, M.E. Sanders, H.R. Gaskins, G.R. Gibson, A. Mercenier, New scientific paradigms for probiotics and prebiotics, Journal Clinical Gastroenterology 37 (2003) $105-118$.

[6] A.E.C. Antunes, E.T.G. Marasca, I. Moreno, F.M. Dourado, L.G. Rodrigues, A.L.S. Lerayer, Development of probiotic Buttermilk, Ciência e Tecnologia de Alimentos 27 (1) (2007) 83-90.

[7] A.E.C. Antunes, E.T. Grael, I. Moreno, L.G. Rodrigues, F.M. Dourado, D.M. Sacarro, et al., Selective enumeration and viability of Bifidobacterium animalis subsp. lactis in a new fermented milk product, Brazilian Journal of Microbiology 38 (1) (2007) 173-177.

[8] F. Haschke, W. Wang, G. Ping, W. Varavithya, A. Podhipak, F. Rochat, et al., Clinical trials prove the safety and efficacy of the probiotic strain Bifidobacterium Bb12 in follow-up formula and growing-up milk, Monatsschr Kinderheilk 146 (1998) S26-S30.

[9] F.G. Denipote, E.B.S.M. Trindade, R.C. Burini, Probiotics and prebiotics in primary care for colon cancer, Gastroenterology Archives 47 (1) (2010) 93-98.

[10] M. Roberfroid, Defining functional foods and associated claims, in: M. Saarela (Ed.), Functional Foods: Concept To Product, Woodhead Publishing Series in Food Science, Technology and Nutrition, Number 205, 2011.

[11] S.A.S Craig, J.F. Holden, J.P. Troup, M.H. Auerbach, H.I. Frier, Polidextrose as soluble fiber: physiological and analytical aspects, Cereal Foods World 43 (5) (1998) 370-376.

[12] S. Kolida, G.R. Gibson, Synbiotics in Health and Disease, Annual Review of Food Science and Technology 2 (2011) 373-393.

[13] M.M. Furtado, J.P.M. Lourenço Neto, Cheese Technology: Technical Manual for Industrial Cheese Production, São Paulo, São Paulo State, Brazil, Dipemar, 1994, p. 105.

[14] H. Michael, J.F. Frank, Standard Methods for the Examination of Dairy Products 4th ed., American Public Health Association, Washington, EUA, 2004.

[15] M. Meilgaard, G.V. Civille, B.T. Carr, Sensory Evaluation Techniques, 4th ed., CRC Press, Boca Raton,
Florida, 2006, p. 448

[16] Adolfo Lutz Institute (IAL), Physicochemical Methods for Food Analysis, 4th ed., São Paulo, São Paulo State, Brazil, 2008.

[17] J.F. Pereira, Chemical Analyses (Bromatology) Federal University of Juiz de Fora, 1975, p. 97.

[18] Ministery of Agriculture, Livestock and Supply [Online], Normative Instruction number 62, Sept. 29, 2011, Section 1, Technical Regulations of Production, Identity and Milk Quality for Raw and Pasteurized Milk, Official Journal of The Union, Federal District, Brazil, http://www.agricultura.gov.br (accessed Sept. 21, 2011).

[19] Ministery of Agriculture, Livestock and Supply [Online], Governmental Regulation number 146, March 7, 1996, Section 1, Technical Regulations of Quality and Identity of Dairy Products. Official Journal of The Union, Federal District, Brazil, http://www.agricultura.gov.br (accessed Sept. 21, 2011).

[20] F.C.A. Buriti, Synbiotic fresh cream-cheese, Master Thesis, Faculty of Pharmaceutical Sciences, São Paulo State University, São Paulo, São Paulo State, Brazil, 2005, http://www.bv.fapesp.br/en/dissertacoes-teses/3972/ synbiotic-fresh-cream-cheese (accessed Sept. 19, 2011).

[21] P. Capela, T.K.C. Hay, N.P. Shah, Effect of cryoprotectants, prebiotics and microencapsulation on survival of probiotic organisms in yogurt and freeze-dried yogurt, Food Research International 39 (2006) 203-211.

[22] F.C.A. Buriti, H.R. Cardarelli, T.M.C.C. Filisetti, S.M.I. Saad, Symbiotic potential of fresh cream cheese supplemented with inulin and Lactobacillus paracasei in co-culture with Streptococcus thermophilus, Food Chemistry 104 (4) (2007) 1605-1610.

[23] National Agency for Sanitary Vigilance (ANVISA) [Online], List of Acceptable Functional Claims number IX, approved at April 2008, http://www.anvisa.gov.br/ alimentos/comissoes/tecno_lista_alega.htm (accessed Sept. 20, 2011).

[24] Ministery of Agriculture, Livestock and Supply [Online], Normative Instruction number 4, Mar. 1, 2004, Section 1, Technical Regulations of Quality and Identity of Minas fresh cheese, Official Journal of The Union, Federal District, Brazil, http://www.agricultura.gov.br (accessed Sept. 20, 2011).

[25] L.L. Alves, Develpoment of symbiotic cream cheese: characterization and lipid profile with emphasis on conjugated linoleic acid, Máster Thesis [Online], Federal University of Santa Maria, Santa Maria, Rio Grande do Sul State, Brazil, 2009, http://cascavel.cpd.ufsm.br/ tede/tde_arquivos/22/TDE-2009-05-13T163113Z-2032/P ublico/ALVES, \%20LARISSA\%20DE\%20LIMA.pdf (accessed Sept. 18, 2011). 